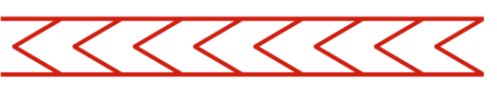

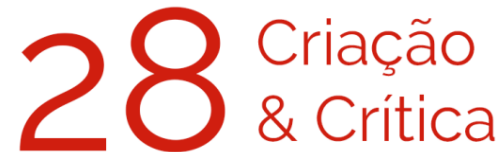

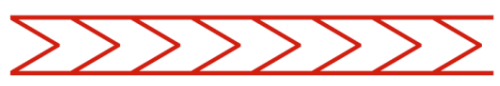

\title{
O CORPO-ESCRITO E O CORPO-LIDO DE (E POR) FRANZ KAFKA
}

\author{
Sâmella Michelly Freitas Russo ${ }^{1}$
}

Resumo: Da leitura da papelada que Franz Kafka deixou, um peculiar corpo se revela. Premido pelo que entendeu como o seu destino literário, ele engendrou para si mesmo, por meio da escrita, uma existência poética ao transformar os seus mundos interno e externo em um corpo escrito. Assim como outros que dedicaram suas vidas à arte, Kafka também manteve sua retórica de clausura, mas não há dúvida de que se valeu do mundo externo para nutrir o interno e elegeu a escrita para registrar a constituição de ambos que, fixados graficamente, compõem um corpo escritural que é dado a circular através da leitura. Nessa conjuntura, corpo-escrito e corpo-lido integram o desejo muito íntimo do autor de dar uma feição ideal ao seu próprio "eu", de dar voz a uma existência que se sentia coagida ao silêncio e a encenar, por meios não tão óbvios, uma comunicação que se perdura no tempo. É recorrendo especialmente aos seus escritos íntimos, como as cartas e os diários, que este artigo pretende demonstrar que confinamento, escrita, leitura e comunicação compõem uma mesma estratégia de fazer circular o seu corpo escritural e, consequentemente, a sua existência, (re)integrando-o a um mundo do qual desde muito cedo sentiu-se apartado.

PALAVRAS-CHAVE: Franz Kafka; corpo; escrita; voz; comunicação; (re)integração.

\section{THE WRITTEN-BODY AND THE READ-BODY OF (AND BY) FRANZ KAFKA}

ABSTRACT: From the reading of the papers that Franz Kafka left an instigating body is revealed. Driven by what he understood to be his literary destiny, he created for himself, through writing, a poetic existence, by transforming his internal and external worlds into a written body. Like others who dedicated their lives to art, Kafka also maintained his rhetoric of isolation, but there is no doubt that he used the external world to nourish his internal one and chose writing to register the constitution of these two worlds that, graphically fixed, make up a scriptural body that is given to circulate through reading. His written-body and his read-body integrate his very intimate desire to give an ideal feature to his own "I", to give voice to an existence that felt coerced to silence and to perform, by means not so obvious, a communication that lasts over time. It is with special reference to his private writings, such as his letters and his diaries, that this article aims to demonstrate that confinement, writing, reading and communication integrate the same strategy to make his scriptural body circulate and, consequently, his existence, (re)integrating him into a world from which he felt separated from a very early age.

KEYWORDS: Franz Kafka; body; writing; voice; communication; (re)integration.

\section{Corpo-confinado}

Por muitas vezes pensei que a melhor maneira de viver para mim seria estar com material de escrita e um abajur no compartimento mais interno de um espaçoso porão trancado. A comida me seria trazida e deixada

\footnotetext{
${ }^{1}$ Universidade de São Paulo.
} 

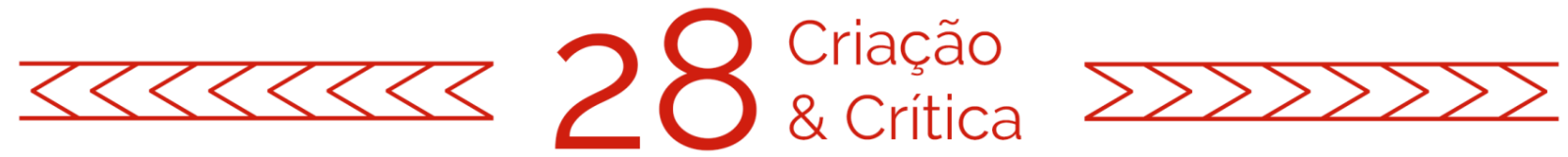

sempre bem longe do meu cômodo atrás da porta mais externa do porão. O caminho até a comida, em meu roupão, através de todas as arcadas do porão, seria o meu único passeio. Então eu voltaria para minha mesa, comeria vagarosa e cuidadosamente e voltaria a escrever em seguida.

A aporia entre vida e escrita sempre foi o conflito essencial do artista que não raro aparta-se - ou é apartado - do mundo, ao que é dado o nome de postura ascética. A declaração acima reflete a vida ideal pela qual anseiam poetas, escritores e artistas que veem na solidão e na retidão a única possibilidade viável de expressar o seu talento. Topos do artista dezenovista, a solidão, a privação e a clausura refletem a condição romântica que envolve o trabalho artístico e integram a retórica daqueles que se veem destinados a uma existência poética. O trecho supracitado foi registrado pelo escritor tcheco Franz Kafka em carta de 14./15.jan.1913 à Felice Bauer e reflete a opinião de seus autores preferidos que, assim como ele, colocavam a arte acima de todo o resto e muito provavelmente celebrariam a identidade do "morador do porão" [Kellerbewohner] formulada por ele (KAFKA, 2015, p. 251). ${ }^{2}$ As correspondências de Flaubert (2005, p. 124; 245) são repletas de conselhos e assertivas semelhantes: "A Arte é bastante vasta para poder ocupar todo um homem. Distrair-se com qualquer outra coisa é quase um crime, é uma falha no dever"; ou "Para um artista, só há um [princípio]: sacrificar tudo à Arte." Também Grillparzer (1903, p. 57), a quem Kafka muito admirava, menciona "um anseio ilimitado pela arte e pelo que a ela pertence" que o fazia perder de vista todas as outras coisas.

Assim como Goethe (1971, p. 29) que ainda menino sentia "um certo furor de rimar e versificar" e Flaubert (2005: 15; a Chevalier, 31.dez.1830) que, aos nove anos, já esboçava suas comédias e dava-as a ler, Kafka manifesta o seu desejo de tornar-se escritor pelo menos desde seus doze anos $(\mathrm{KOCH}, 1995$, p. 25). Junto da papelada pessoal deixada por ele, é bastante comum deparar-se com declarações suas a respeito do seu "destino literário" [litterarische Bestimmung], responsável por impedi-lo de se envolver efetivamente em qualquer outra coisa que não a literatura e a escrita, únicas instâncias vistas como correspondentes à sua peculiar natureza (KAFKA, 2014, p. 241; 2.mar.1912). ${ }^{3}$ Em meio aos cursos de ação disponíveis a ele - dentre os quais esteve ser funcionário, advogado, pai de família, judeu -, Kafka definiu na escrita o seu propósito primevo. Visando ao cumprimento desse propósito, teve que empenhar esforços e optar por uma espécie de via de desvio, refletidos em uma longa luta que foi registrada nos seus escritos pessoais os doze diários, os relatos de viagem, parte dos cadernos in-oitavo e as cartas.

"Perverso é aquilo que desvia" (KAFKA, 1966, p. 84) e o "esquecimento de si mesmo é o primeiro pré-requisito do escritor" (KAFKA, 1958, p. 385; a Brod, 5.jul.1922), advertia ele com frequência. Dentre o que supostamente perturbaria a sua escrita e a sua

\footnotetext{
2 Todas as traduções de trechos retirados de obras estrangeiras são minhas. Em relação às citações dos diários de Kafka, foi utilizada a tradução de Isabel Castro Silva com eventuais modificações feitas por mim. Quando houver intervenção minha nas traduções desses diários, vocábulos e sentenças serão sublinhados. ${ }^{3}$ No caso dos diários e das cartas citados de Kafka, para facilitar eventual consulta dos trechos, foram indicados as datas e os destinatários das missivas assim como as datas das entradas.
} 

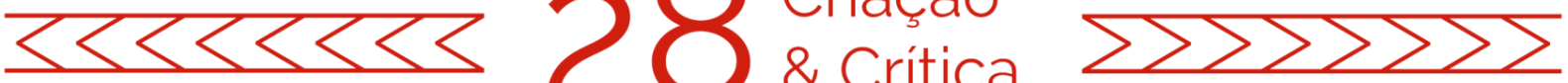

relação com a literatura estariam o seu trabalho no Instituto de Seguros, as idas à fábrica do cunhado, a família, as mulheres, o sexo. ${ }^{4}$ Reiteradamente afirma ser a literatura a sua "única aspiração e ofício" e tudo que escapasse a sua lógica deveria ser sacrificado em nome da escrita (KAFKA, 2014, p. 356; 21.ago.1913): o Instituto onde cumpre atividades como funcionário público é designado sempre como escritório [Bureau], pois o verdadeiro ofício [Arbeit] era realizado junto de sua escrivaninha (KAFKA, 2014, p. 23; 19.fev.1911); a coação de ter que ir à fábrica o atormenta e priva das horas dedicadas à escrita (KAFKA, 2014, p. 200; 28.dez.1911); os membros da família atrapalham a concentração necessária para suas atividades literárias (D 39; 5.out.1911); Felice, sua noiva por duas vezes, é vista por ele como a maior inimiga do seu trabalho literário (KAFKA, 2015, p. 691; prov. 1‥/2.nov.1914).

Convencido de seu chamado e destino poéticos, ele conjectura fantasias monasteriais que veem no "morador do porão" o melhor aliado na consecução da sua tarefa: "Viver o mais asceticamente possível, mais asceticamente que um celibatário", adverte a si mesmo (KAFKA, 2014, p. 353; 14.ago.1913). Retidão e clausura são quesitos levados em conta na configuração da existência poética de Kafka ao eleger para si sua elementar identidade: ser escritor, ser escritura. Literatura e escrita são meios de investigação do próprio eu, instrumentos por meio das quais ele pôde ter acesso à sua essência interior e compreender o mundo que o cercava. É, portanto, essa eleição que o impele a adotar estratégias ascéticas: não se casou - não obstante os "três" noivados; ${ }^{5}$ não teve filhos; não constituiu assim família; não consumia álcool ou drogas; era vegetariano e rejeitou até mesmo os laços com a própria família: "eu descendo dos meus pais, o sangue liga-me a eles e às minhas irmãs, não o sinto na vida quotidiana nem nos meus objetivos particulares" (KAFKA, 2014, p. 499; 18.out.1916). ${ }^{6}$ Não escrever por conta de qualquer uma dessas outras instâncias equivale "necessariamente à total aniquilação" da sua existência (KAFKA, 2014, p. 200; 28.dez.1911) e afasta-o do atingimento de seu propósito.

\footnotetext{
${ }^{4}$ Com isso não se pretende afirmar que Kafka fosse um asceta sexual, tal como muito se vê propagado na crítica dedicada a ele, visto que foi um contumaz frequentador de bordéis, o que pode ser facilmente depreendido pela leitura dos seus diários. Algumas das entradas de suas notas nas quais prostitutas e bordéis são mencionados foram suprimidas por Brod quando da primeira edição dos diários em 1937, o que muito provavelmente colaborou para essa imagem por anos. A título de exemplo, conferir KAFKA, 2014, pp. 13; 32; 34; 610; 644; conferir também carta à Milena de 8./9.ago.1920.

${ }^{5}$ Kafka foi noivo duas vezes de Felice Bauer (1914 e 1917) e uma vez de Julie Wohryzek (1919). Nenhum noivado foi levado adiante.

${ }^{6}$ É provável que Kafka tenha conhecido um popular movimento na virada do século e ao qual ele tenha aderido em suas leituras da revista Der Kunstwart, fundada em 1887. O Lebensreform [Reforma da vida] defendia um modo de viver que retomasse práticas mais naturais, desde alimentação até disposição de móveis (STACH, 2015, p. 214). Esse retorno à natureza tinha dentre suas orientações a opção por refeições saudáveis, a prática do nudismo e da liberdade sexual, a abstenção de substâncias nocivas à saúde, como álcool, tabaco, drogas, além de propalar os benefícios da medicina alternativa. A isso, Kafka tinha outros hábitos que poderiam ser considerados excêntricos: além de seu vegetarianismo, praticava exercícios regulamente, assim como o método de mastigar diversas vezes; dormia com as janelas abertas, além da sua conhecida resistência à medicina tradicional. Tudo isso também colaborou para dar forma ao seu desejado ascetismo em prol da arte.
} 

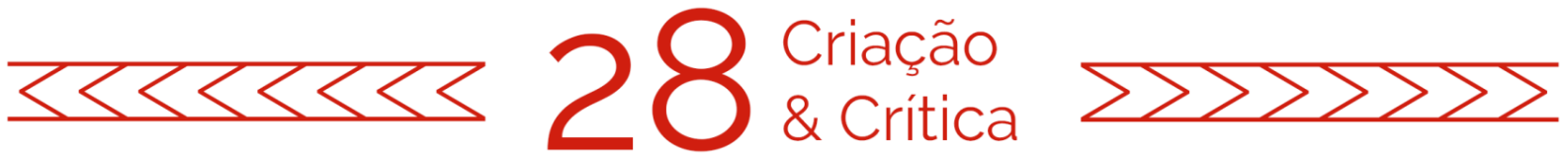

No quesito literatura, há junto a Kafka sempre uma exclusão mútua em que qualquer conciliação é impossível: literatura ou casamento; literatura ou fábrica; literatura ou instituto; literatura ou filhos. Sendo confessadamente a literatura o seu "destino inalterável" [unabänderliche Bestimmung] (KAFKA, 2015, p. 491; a Carl Bauer, prov. 28.ago.1913), instala-se o conflito que o assolou ao longo de toda a vida, testemunhado especialmente pelas notas dos seus diários. Desse conflito e das "recusas" a que se viu forçado em nome da escrita resultaram predicados como um homem aflito com autismo social, por exemplo (BINDER, 1976, p. 47 e STACH, 2017b, p. 104). A seu ver, porém, o que precisava fazer só poderia ser feito sozinho (KAFKA apud BROD, 1963, p. 176), e a insociabilidade advinda disso seria mero reflexo do destino do qual não poderia esquivarse (KAFKA, 2014, p. 356; 21.ago.1913). Neste momento, é instigante refletir sobre a sugestão feita por Stach (2015, p. 87): "Se acreditarmos em sua própria mitologia privada, ele migrou da vida para a literatura, sem regresso. Mas e se fosse o oposto e a literatura fosse para ele a única maneira viável de retorno?"

Essa é inclusive sugestão dele próprio. Tanto nos diários quanto nas cartas, frequentes são as notas que expressam a equivalência absoluta entre escrita e vida: a escrita é aquela apta a conceder o "espaço para viver", a fazer dele um ser vivo (KAFKA, 2014, pp. 417; 30.ago.1914 e 38; 3.out.1911). A leitura de seus papéis pessoais não deixa dúvidas de que, para ele, a escrita é uma maneira legítima de viver, em que, juntas, literatura e escrita eram antes de tudo instrumentos que tinham a faculdade de lhe propiciar a "verdadeira vida" (KAFKA, 2014, p. 208; 3.jan.1912), e isso talvez porque cumprissem junto dele uma função compensatória. Muitos são os registros do seu sentimento de alheamento e estrangeiridade no mundo: da própria família, sente-se afetivamente afastado (KAFKA, 2015, p. 503; 29.out.1913 e KAFKA, 2014, p. 435; 5.dez.1914); na sociedade, sente-se um "estrangeiro", um cidadão de um outro mundo (KAFKA, 2014, p. 556; 28.jan.1922). Não surpreende, portanto, que a escrita, assim como o trabalho literário, dê-lhe o "direito à vida", de onde advém sua necessidade premente de zelar por ela (KAFKA, 2015, p. 695; 1.2./nov.1914). Mesmo os relacionamentos amorosos e fraternos atestam essa prerrogativa, sendo bastante conhecida a relação que ele mantinha com as cartas, que tiveram como os seus principais destinatários Felice, Milena e Brod, de modo que o contato físico foi, em geral, preterido pelo gráfico, especialmente no caso das mulheres.

$\mathrm{Na}$ lógica estabelecida por ele, é por serem escritas que as cartas lhe servem de elo com o mundo, ou seja, é mesmo um modus vivendi. Seja no caso daquela que foi sua noiva por duas vezes, Felice, seja no de Milena, com quem também manteve um intenso envolvimento, a relação foi, de fato, eminentemente epistolar. Em ambos os casos, estáse diante de relações ausentes: sete meses separam o primeiro do segundo encontro entre Kafka e Felice, período durante o qual foram conservadas quase duas centenas de 

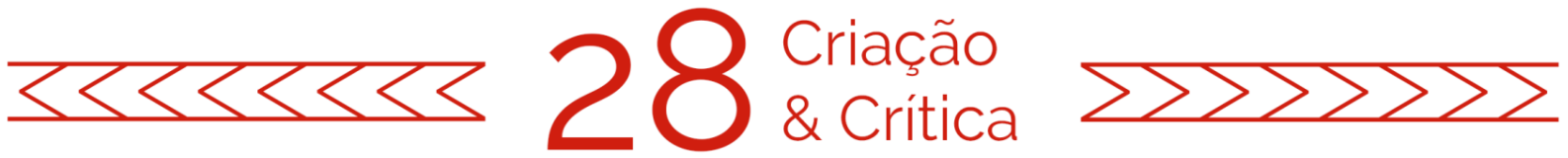

missivas enviadas por ele; ${ }^{7}$ Milena e Kafka se encontraram pessoalmente apenas por cinco dias, e por todo o resto do tempo o contato prescindiu da presença física, dando ensejo apenas à troca de correspondências (ROTHER, 2007, p. 202). É através da escrita que ele experimenta a verdadeira vida, razão que o impele a rechaçar qualquer outra forma de existência.

Da leitura dos seus diários, porém, não fica claro se a postura ascética e reclusa mantida - e mesmo desejada - por ele em nome da sua atividade escriturária é fruto de uma decisão própria ou de circunstância alheia a ele. Em entrada de 16.jan.1922, ele registra essa dubiedade: "A solidão, a que em grande medida fui desde sempre forçado, mas que em parte procurei - mas esta busca que outra coisa era senão coerção?" (KAFKA, 2014, p. 546) Seria, assim, essa solidão uma exigência sine qua non do artista ou alternativa a um rechaço que lhe foi antes imposto. De todo modo, qualquer pessoa que leia e se familiarize com seus diários e suas cartas preservadas se surpreenderia com o protagonismo dado à escrita como tema, ora refletido na atividade literária, ora no ato de escrever em si.

Escrever é para ele "a coisa mais importante na Terra" e vai-lhe desempenhar inúmeras funções, dentre as quais a de auxiliá-lo na compreensão da própria existência, de fazer companhia ao mitigar os efeitos da solidão, de autopreservação e mesmo de sobrevivência (KAFKA, 1958, p. 431; a Klopstock, final de mar.1923). É sentindo-se estranho e alheado do mundo exterior que o cerca que a escrita vai servir especialmente a duas finalidades proeminentes: comunicativa e integrativa. Mas porque precisamente a escrita? Em nov.1919, na famosa carta ao pai, Kafka se vale do gesto escriturário para responder, em mais de cem páginas, a uma pergunta:

Querido pai

Você me perguntou recentemente por que eu afirmo ter medo de você. Como de costume, não soube responder, em parte justamente por causa do medo que tenho de você, em parte porque na motivação desse medo intervêm tantos pormenores, que mal poderia reuni-los numa fala. $E$ se aqui tento responder por escrito... (KAFKA, 2013, p. 7; destaque meu)

A tentativa de elaborar essa célebre e longa resposta "por escrito" tem várias motivações. Junto dele, "escrever" [schreiben] tem sempre prevalência à "fala" [Rede], pois sobre essa atuariam "incessantemente milhares de formalidades e constrangimentos externos". Contrastando a articulação vocal inerente à fala e o gesto gráfico da escrita, conclui que escrever é a única forma de expressão adequada a ele (KAFKA, 2015, p. 484; 20.ago.1913). Ainda na carta endereçada - mas não enviada - ao pai, encontra-se explícito o preterimento da fala em detrimento da escrita, quando ele declara que a relação dos dois teve entre as suas principais consequências a de ele ter desaprendido a falar, impelindo-o a uma espécie de mutismo:

\footnotetext{
7 Para Canetti, (1988, p. 17 ss.) a troca epistolar com Felice tinha o propósito de dar vazão a sua criação literária e lhe servia como "fonte de energia" e, não por acaso, duas noites depois da primeira carta ele teria escrito Das Urteil [O veredicto].
} 

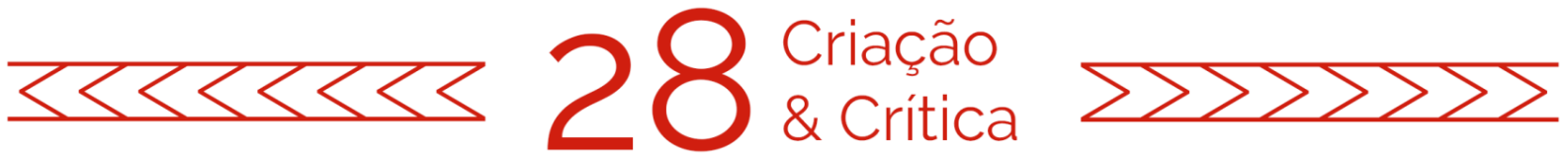

A impossibilidade do intercâmbio tranquilo teve uma outra consequência na verdade muito natural: desaprendi a falar. Certamente eu não teria sido, em outro contexto, um grande orador, mas sem dúvida teria dominado a linguagem humana corrente e comum. No entanto, logo cedo você me interditou a palavra, sob ameaça: 'Nenhuma palavra de contestação!' e a mão erguida no ato me acompanharam desde sempre. Na sua presença quando se trata das suas coisas você é um excelente orador - adquiri um modo de falar entrecortado, gaguejante, para você também isso era demais, finalmente silenciei, a princípio talvez por teimosia, mais tarde porque já não podia pensar nem falar. $\mathrm{E}$ como você era meu verdadeiro educador, isso repercutiu em todos os aspectos da minha vida (KAFKA, 2013, p. 21 ss.).

Sentindo-se coagido na expressão verbal e interessado em fazer comunicar a sua existência, ele se vê obrigado a engendrar outra via comunicativa do que deriva sua certeza de que suas habilidades escriturárias excedem em muito às vocais: "não seria melhor se eu falasse tal como eu escrevo?" (KAFKA, 2015, p. 724; 9.ago.1915) É ainda preciso ressaltar que Kafka, ao contrário do que muitos apregoam, não era um indivíduo desinteressado no mundo exterior e indiferente às pessoas. Já aos vinte anos, ele compreende e pressagia a necessidade do outro: "alguém que fica atrás da árvore me diz, em voz baixa: 'Você não vai fazer nada sem os outros'” (KAFKA, 1999, p. 17; a Oskar Pollak, 6.set.1903). Mais tarde e não obstante a retórica de reclusão, ele próprio admite sentir "ânsia por pessoas" (KAFKA, 1958, p. 101; a Brod, 22.jul.1912). A aproximação delas fica, todavia, impedida pelo "medo" e pelo constrangimento, pois a pessoa que visa ser - destemida, sem máscaras, poderosa, surpreendente, emotiva - só poderia, a seu ver, ser expressa escrituralmente (KAFKA, 2014, p. 350; 21.jul.1913). E o que é a literatura senão uma possibilidade premente de comunicação com o outro?

Apesar das eternas queixas de não dispor de tempo suficiente para sua escrita e seu trabalho literário, Kafka sempre se preocupou em manter precisos elos com o mundo externo, mesmo porque uma renúncia completa à vida teria colocado a própria escrita em risco. Afinal, a "arte não é [...] uma entidade esotérica; ela suga seu próprio alimento da vida vivida" (GRÄSER, 1955, p. 99) e, como declara certeiramente Flaubert (2005, p. 82), é "difícil exprimir bem o que nunca se sentiu". Por tudo isso é preciso não superestimar essa "renúncia" à vida junto dele, pois é sabido que a sua atividade como funcionário público contribuiu grandemente para a formulação dos seus mundos ficcionais, o que fica especialmente explícito em seus três romances inacabados - Der Verschollene [O desaparecido], Der Prozess [O processo] e Das Schloss [O castelo] -, assim como Felice, sem a qual muito provavelmente sua novela Das Urteil [O veredicto] não teria sequer surgido. Ademais, os outros - tal como ocorre na sua prática epistolar - garantem a ele esse elo necessário com um mundo do qual se sentiu sempre afastado: "Você era", escreve ele ao amigo Oskar Pollak, "comparado a muitos outros, algo como uma janela pra mim, pela qual eu podia observar a rua. Sozinho eu não podia, pois, apesar do meu tamanho, eu não alcanço o peitoril da janela." (KAFKA, 1958, p. 20; 9.nov.1903) 

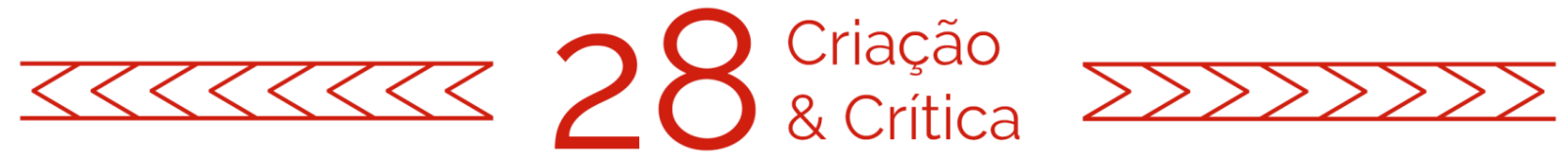

Sem romper definitivamente com o externo e ao traduzir linguisticamente sua vida interior, literatura e escrita possibilitam a sua comunicação com o mundo, transmitindo "tudo o que em mim [nele] há de bom" (KAFKA, 2014, p. 227; 4.fev.1912), com o que ele insinua que sua pessoa-escrita é a apta a revelar o seu melhor e mais bonito "eu". É precisamente isso que ele sugere quase uma década antes, quando revela: "É bom quando se pode encobrir a si mesmo com palavras, mas ainda melhor é se puder adornar e florear a si com palavras até se tornar a pessoa que se deseja em seu coração" (KAFKA, 1958, p. 26; a Oskar Pollak, 10.jan.1904; destaque meu). Duas ideias são aqui expressamente reveladas: o desejo de ter domínio sobre si mesmo e a manipulação da palavra que poderia colaborar para a concretude desse desejo, manifestando uma espécie de gesto performático a que se prestaria o ato de escrever. É escrevendo que ele conhece a si mesmo e molda tal conhecimento adquirido para, finalmente, dar esse "eu" a ser conhecido a um outro, ou seja, é assim que ele transita de um corpo-em-confinamento a um corpo-escrito.

\section{Corpo-escrito}

"Não tenho nenhum interesse em literatura, mas sou literatura; não sou nada além disso e não poderia ser outra coisa." (KAFKA, 2015, p. 479; 14.ago.1913) Essa tão citada declaração reflete de maneira muito evidente o discurso retórico de que Kafka se vale na formação de uma identidade absolutamente literária-escritural que define toda a sua singular existência. Sempre à "caça de construções" [Jagd nach Konstruktionen], a escrita foi o método ao qual ele recorreu para edificar essa identidade, pois, ao atuar como escritor, fez dele mesmo o objeto do seu trabalho - a escrita -, engendrando para si um novo corpo, melhor, mais ousado e perene. É isso que Kafka quer dizer quando afirma não ter inclinações para escrever, mas que a escrita é ele mesmo (KAFKA, 2015, p. 488; 24.ago.1913); ou que "todo o meu ser é direcionado à literatura [...]. Tudo o que eu sou e não sou é derivado disso" (KAFKA, 2015, p. 490; a Carl Bauer, prov. 28.ago.1913); ou ainda que tudo aquilo que não é literatura o aborrece (KAFKA, 2014, p. 349; 21.jul.1913). É desse modo que ele não é apenas escritor; ele é literatura, escritura, ou seja, ele não apenas realiza o ato de escrever como se torna o próprio efeito desse ato. Daí o fato de não surpreender que o registro da sua atuação como ser-social, seja junto à sua família, aos amigos, às mulheres, ao trabalho etc., passe necessariamente por esse viés de identidade, que prestam provas à literarização da sua vida, testemunhada tanto nos diários quanto nas cartas, mesmo porque, como ele insistentemente insinua, sua existência só poderia acontecer por escrito.

Quando afirma "O romance sou eu, minhas histórias sou eu" (KAFKA, 2015, p. 223; 2./3.jan.1913), é quase irresistível equiparar obra e autor, mas não se trata disso. Então, o que quereria ele dizer com tudo isso? Em Kafka, literatura e escrita participam de uma dinâmica indissociável que pode levar a uma confusão metonímica. A primazia não é absolutamente da literatura, que é apenas um meio através do qual a escrita é 

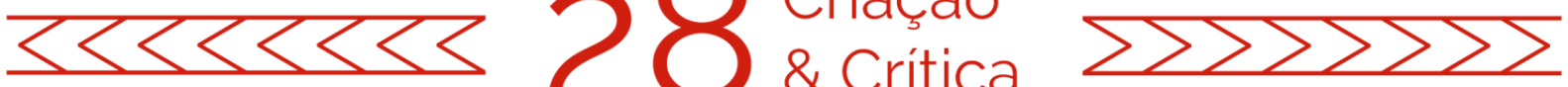

instrumentalizada. Muito acertadamente, Schärf (2000, p. 69) adverte que a declaração de não se interessar por literatura, mas ser literatura, não deve ser apreendida metaforicamente, não significando, portanto, uma dedicação absoluta à literatura; o que ele quereria dizer como isso é: "Meu corpo é escrita [Schriff]", devendo "literatura" ser compreendida de modo abrangente, pois ele não estaria se referindo de modo exclusivo a sua obra ficcional, mas à escrita como um todo, fosse ela a pessoal, a ficcional, a burocrática. Junto desse discurso de equiparação absoluta, Kafka toma por objeto a si mesmo, ou seja, o objeto oriundo da atividade de escritor é transformado em prolongamento do seu próprio corpo. ${ }^{8}$ Não por acaso ele guarda uma relação visceral com sua escrita. Quando da redação de Das Urteil [O veredicto] diretamente nos diários na noite do dia 22 para 23 de setembro de 1912, ele compara o surgimento da história a um "autêntico parto" (KAFKA, 2014, p. 274-283 e p. 301; 11.fev.1913). Flaubert (2005, p. 184), um de seus autores mais cativos, já afirmava que um livro é uma "uma maneira especial de viver, um meio de me inserir num certo ambiente." Kafka compreende sua escrita de modo análogo: cada história gestada, impressa e publicada era uma forma eficiente de colocar-se em circulação. Ser escritor a seu modo tem, portanto, inúmeras vantagens: dá origem e forma à sua existência que passa a ter a prerrogativa de ser comunicada e interagida com o mundo. Daí mesmo decorre da escrita ser constantemente encenada por ele. Na leitura de seus diários e cartas, são frequentes as chamadas "cenas de escrita" [Schreibszene], ou seja, a descrição de episódios que se referem a elementos não vinculados exclusivamente ao poeta-escritor. Nessas cenas, é integrado todo o material disponível que envolve o processo poético, ou seja, os "fatores externos que, em sua totalidade, colaboram para dar sentido ao processo de escrita material" (SIMON, 2018, p. 43 ss.). Por meio desse procedimento, o instrumento usado para escrever, o movimento da mão, o tipo de papel, a organização da escrivaninha, a luz, o ruído, isto é, todo o espaço cênico que cerca o ato criativo da escrita passa a compor o texto, incluindo o próprio escritor, feito também protagonista. Escritor e objetos interagem por meio de um "imperativo do gesto" (CAMPE, 2015, p. 279) que reflete o momento preciso da criação artística.

Miserável, miserável, e no entanto bem-intencionado. É meia-noite, mas isso, uma vez que dormi bem, só seria desculpa se durante o dia tivesse escrito alguma coisa. O candeeiro aceso, a casa em silêncio, a escuridão lá fora, os últimos momentos de vigília dão-me o direito de escrever, mesmo as coisas mais miseráveis (KAFKA, 2014, p. 88; 25.dez.1910).

É precisamente isso o que Kafka fez nessa entrada de seu diário, ao encenar o próprio ato de escrever, também tomado sob uma perspectiva literária, quando ele esclarece não apenas características suas (miserável e bem-intencionado) como também aponta o local e a hora em que se dá a escrita, o que agrega aos elementos cênicos que compõe a cena, como a luminosidade do candeeiro e a ausência de som no ambiente.

\footnotetext{
${ }^{8}$ Esse é muito provavelmente o principal aspecto que leva muitos a concluírem pela presença contínua da biografia do autor em sua ficção, em maior ou menor grau (ROTHER, 2007, p. 71).
} 

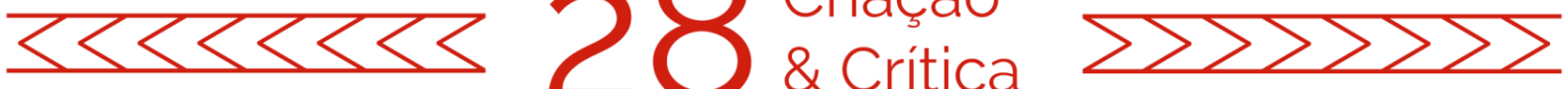

Em verdade, é a descrição do local de trabalho do escritor por excelência. Também esse é um valioso procedimento na constituição desse corpo escriturário em formação que, porém, não pôde prescindir de corpos alheios a ele.

\section{Corpo-alheio}

No processo de autoconhecimento e de formação identitária, o sujeito com frequência recorre a outras pessoas, que desempenham a função de verdadeiros modelos, fazendo desse processo constitutivo de si um ato não-solitário. É por ter previamente eleito a sua forma de "ser" no mundo que também Kafka vai escolher cautelosamente as referências de que necessita para ser bem-sucedido no seu propósito. Lembremos que imitar é instinto inato: "O imitar é congênito no homem (e nisso difere dos outros viventes, pois, de todos, é ele o mais imitador, e, por imitação, apreende as primeiras noções)" (ARISTÓTELES, 1994, pp. 106 ss.). A imitação assim é instrumento pedagógico que concede ao sujeito-imitador a faculdade de desenvolver determinados gestos, habilidades. O próprio Kafka registra em seus diários a sua forte capacidade para metamorfosear-se [starke Verwandlungsfähigkeit], bem como um "instinto de imitação" [Nachahmungstrieb] (KAFKA, 2014, pp. 33; 30.set.1911 e 201; 30.dez.1911). Para imitar, porém, é preciso antes que ele determine qual modelo é digno de ser imitado [nachahmenswert] (KAFKA, 2014, p. 497; 27.ago.1916), pois, como ele mesmo disse em relação aos atores de teatro, o que define o mau artista "não é imitar mal, mas sim [...] imitar modelos errados" (D 202; 30.dez.1911). Ao acessar os livros que mantinha em sua "biblioteca", nota-se que ele foi um ávido leitor de diários íntimos, relatos de viagem e expedição, cartas, biografias, autobiografias e memórias. Por meio da leitura dessas narrativas de vida, ele buscava conformar uma própria identidade para si, elegendo, para tanto, escritores que vai considerar seus verdadeiros "parentes de sangue" [Blutsverwandten] como Grillparzer, Dostoievski, Kleist e Flaubert (KAFKA, 2015, p. 494; 2.set.1913).

Chama a atenção a admiração que Kafka cultivou desde muito jovem por artistas que colocaram a arte acima de tudo em suas vidas. Goethe e Flaubert desempenharam assim o papel de modelos mais expressivos junto dele. No poeta alemão, admirava particularmente a trajetória da sua vida, tendo lido praticamente tudo que dizia respeito a sua pessoa, como diários, notas de viagem, memórias, biografias, autobiografia. Admirava ainda o seu tratamento com a língua alemã e especialmente a sua confessada e ilimitada vontade de criar (KAFKA, 2014, pp. 80 e 231; 16.nov.1910 e 8.fev.1912). Segundo Jurgensen (1979, p. 44), compartilhava com Goethe a tendência de transformar a vida em literatura. Quanto ao escritor francês, as afinidades são ainda maiores. Ambos viam na literatura a forma ideal de vida, para o que uma postura ascética era imprescindível, daí não terem se casado; nos dois casos, o contato com as mulheres se deu primordialmente através de cartas, além da formação jurídica e a recusa em atuar nessa área. Flaubert é então não apenas um importante modelo eleito por ele, mas 

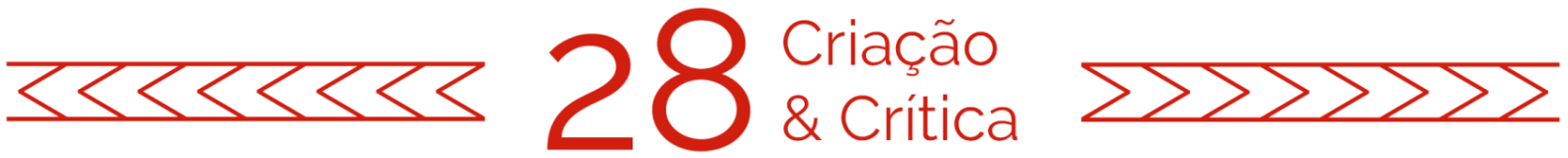

também aquele de quem Kafka se considerava um "filho espiritual" [geistiges Kind] (KAFKA, 2015, p. 69; 15.nov.1912).

Ao eleger as suas leituras modelares, Kafka procurava compreender o modo de operação e atuação desses modelos no mundo, buscando exemplos de uma vida reta, ascética e dependente da escrita, ou seja, buscando pessoas com as quais partilhava valores, posturas e propósitos. Ao elencá-los, não apenas arquitetava "estratégias de afirmação" (STACH, 2017a, p. 484) como examinava referências na conformação da sua própria existência, no que se pode dizer que foi bem-sucedido. Goethe, Flaubert, Hebbel, Kierkegaard e Grillparzer cumprem assim uma importante função no seu processo de compreensão e constituição da própria identidade, ao permitirem a ele criar "para si mesmo uma tradição, uma linha de descendência" (STACH, 2017a, p. 373). É desse modo que Kafka recorre também a outros corpos na formatação do seu próprio.

\section{Corpo-lido}

Ainda que Kafka insistisse que a única forma de expressão apropriada para ele fosse a escrita, não se deve negligenciar a sua "especial paixão" pela leitura em voz alta, prática bastante popular nos circuitos literários no final do século XIX e início do $X X$. Recitação de textos em salões de leitura fazia parte, segundo Schneider (2008, p. 23), de uma ideia em voga na época de que a qualidade do texto em prosa dependia estreitamente da sua possibilidade de ser lido em voz alta, de forma que um eventual sucesso de determinado texto estivesse ligado ao desempenho dessas leituras nesses salões. Essa paixão cultivada por Kafka pode ser depreendida não apenas da leitura das suas notas íntimas como também de testemunhos de amigos que o descreviam como um "maravilhoso leitor em público" (KOCH, 1995, pp. 68 e 71).

"Vociferar", declara ele, "nos ouvidos preparados e atentos dos ouvintes faz tão bem ao pobre coração" (KAFKA, 2015, p. 138; 4./5.dez.1912). Nessa carta, faz menção a um sonho de quando era criança, que consistia em impressionar um grande público com a sua performance vocal em uma sala repleta de pessoas; no sonho, a leitura duraria dias a fio. Ato intimamente derivado da escrita, esse tipo de leitura guarda estreita relação com o que ele entendia como sua tarefa quase messiânica de guiar e influenciar as pessoas (BrF 858; 30.set.1917). No curso da vocalização do texto, o leitor toma parte naquele pequeno fragmento do mundo e participa, de alguma maneira, da vida dos ouvintes, e a mera possibilidade dessa influência e de provocar o "deleite público" geravam nele satisfação pessoal: "Você sabe que comandar pessoas ou no mínimo acreditar que as comanda - não há conforto maior para o corpo" (KAFKA, 2015, p. 138).

Com certa frequência, Kafka lia publicamente textos de outros autores como Wilhelm Schäfer, Flaubert, Grillparzer, Kleist (Cf., p. ex., KAFKA, 2014, pp. 132; 31. out.1911 e 375; 11.dez.1913), mas é da leitura de seus próprios textos que retira os maiores benefícios. É lendo Vor dem Gesetz [Diante da Lei] para Felice que adquire melhor conhecimento sobre seu relato: "Eu só nesse momento percebi o significado da 

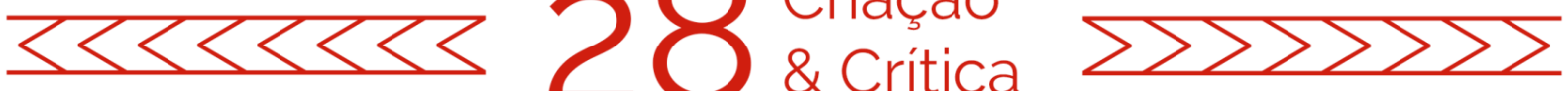

história" (KAFKA, 2014, p. 446; 24.jan.1915). Após mencionar em uma entrada de seus diários uma leitura feita diante de amigos de uma curta narrativa sua, ele confessa:

Se alguma vez conseguisse escrever uma coisa completa, extensa, bem formada do princípio ao fim, então a história nunca se poderia libertar de mim com um corte definitivo, e eu poderia assistir tranquilamente e de olhos abertos, como o parente consanguíneo de uma história saudável, à sua leitura em público (KAFKA, 2014, p. 139 ss.; 5.nov.1911)

É lendo diante do público que ele se torna crítico da sua escrita, aponta falhas e busca fazer erguer dentro dele "todas as possibilidades do meu [seu] talento". Para além do ganho de inteligibilidade e de confiança, a leitura diante do outro permite que ele se aproxime fisicamente da coisa escrita e chegue mesmo a fundir-se com ela, tornando corpo e escrita uma única coisa (KAFKA, 2014, p. 213; 4.jan.1912). É dessa maneira que, por meio desse ato, ele incorpora a si mesmo na obra lida, vincula-se corporalmente a ela e adquire nova configuração identitária (KAFKA, 2014, p. 213; 4.jan.1912). Há ainda um importante aspecto a ser considerado: a performatividade a que se submete o gesto da leitura em público. Ao ler em voz alta, de certa forma, o que o leitor faz é dramatizar o texto escrito, e os textos de Kafka se ajustam muito bem a esse tipo de expressividade. Thieberger (1979, p. 198) vai dizer que essa é uma prerrogativa que Kafka compartilhava com outro autor de língua alemã, Heinrich von Kleist, cujas histórias não apenas eram concebidas para que fossem vocalizadas sobre o palco, como seu sentido só se tornaria acessível quando lidas dessa maneira. Dentre os seus próprios textos que Kafka leu em voz alta, ora diante da família, ora diante de amigos, ora diante de público maior desconhecido, estão: Die Verwandlung [A metamorfose], Das Urteil, [O veredicto], Der Heizer [O fogueiro], In der Strafkolonie [Na colônia penal].

Junto da performance vocal, é preciso estar atento à precisão do timbre, à entonação, aos gestos que acompanham as sentenças, à sonoridade, ao ritmo. Todo esse cuidado diante da coisa a ser lida advém de um objetivo bastante preciso: através dela, ele visa "ser recompensado". É ele mesmo a esclarecer no que consistiria essa recompensa: sua intenção essencial era causar efeito no público, de modo a possibilitar que ele próprio participasse "igualmente, sob o efeito encobridor da vaidade, em toda a influência que a própria obra exerceu." (KAFKA, 2014, p. 213; 4.jan.1912) Fundido na coisa lida, ao ler o texto, o que ele faz é interagir a si próprio com esse público, com o que se atende a uma satisfação confessadamente egóica, pois tal postura serve para atender à vaidade do detentor da voz, aspecto que ele confessa reiteradas vezes em seus diários (KAFKA, 2014, pp. 213; 4.jan.1912 e 344; 24.mai.1913). Na comunicação encenada e estilizada propiciada pela leitura em público, a linguagem cumpre a função identificada por Luhmann (1997, p. 249), qual seja a de "meio de comunicação oral", com o que "a sociabilidade é como que automaticamente garantida": "Orador e ouvintes ouvem a mesma coisa e, ao ouvir o que ele diz, o orador se inclui na comunidade de ouvintes." Isso leva a compreender a importância desse ato junto a Kafka, pois essa leitura é também meio eficiente para imiscuir-se em um contexto social, além de ter outra 

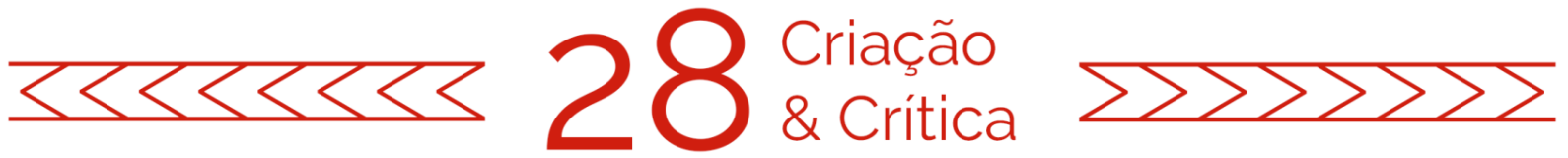

vantagem: a satisfação e a sensação de receber com ela um pequeno "reconhecimento" geram nele um sentimento de estar apto a dar continuidade a sua tarefa literária, ensejando "quase o começo de uma realidade de uma bela existência" (Cf., p. ex., KAFKA, 2014, pp. 285; 25.set.1912 e 434; 2.dez.1914 e ibid., 2015, p. 330 ss.; 1‥/2.mar.1913).

\section{Corpo-comunicado e (re)integrado}

A constituição de um corpo-escrito e de um corpo-lido participam de uma mesma dinâmica muito útil a Kafka. Ao fazer de si próprio escritura, tanto o registro gráfico quanto a leitura dessa inscrição corpórea envolvem o outro em um processo de comunicação. Ambos atuam na transmissibilidade da sua existência, ora de modo mais imediato, ora mais duradouro. Por um lado, sendo a instrumentalização vocalizada da fala aquilo que proporciona ao indivíduo a transmissão de suas ideias, reflexões e pensamentos, a leitura do texto corpóreo por ele próprio permite o envolvimento do outro nesse ato interlocutório; por outro lado, tendo Kafka desaprendido a falar, o corpo-escrito, fixado no papel, pôde ser levado adiante, comunicando sua existência perpetuamente ao mundo, no que desempenharam papéis fundamentais os seus diários, as suas cartas enviadas a outros e os textos ficcionais. Para ele que confessa medo e constrangimento na sua interação com o mundo, a escrita ainda tem a vantagem de permitir uma comunicação ausente e, portanto, sem constrangimentos, além de se perpetuar de maneira mais eficiente no tempo e atingir maior número de pessoas, assemelhando-se a uma mensagem ao futuro para destinatários incertos. Essas são inclusive algumas das principais utilidades da escrita apontada por Luhmann (1997, p. 257): o advento da escrita permitiu a "acessibilidade comunicativa daqueles ausentes no espaço e no tempo."

Ainda que discursivamente o outro seja objeto de rechaço, ele é indispensável tanto na compreensão desse corpo em constante formação, quanto na sua comunicação, pois é junto dele que esse corpo interage, garantindo-lhe alguma perpetuidade e permitindo que se participe do experimento que é a vida. Sendo Kafka literatura, sendo ele próprio esse corpo escrito, a leitura em voz alta de seus próprios textos e o ato de escrever são gestos integrativos que visam promover a sua participação mais livre e encorajada na sociedade. Tendo tudo isso em vista, o seu corpo-confinado revela propósitos bastante ambiciosos. Em um de seus aforismos, ele insinua uma ideia de grandeza imbuída na feitura desse corpo-escritura:

Não é necessário que você saia de casa. Fique junto à sua mesa e escute. Nem mesmo escute, só espere. Nem mesmo espere, fique totalmente em silêncio e sozinho. O mundo irá oferecer-se a você para o desmascaramento, ele não pode fazer outra coisa, extasiado ele irá contorcer-se a seus pés (KAFKA, 2012, p. 112).

Diferentemente do que muitos apregoam, Kafka não escrevia para uma autossatisfação, e prova disso é sua "luta silenciosa" para ver publicados todos os textos 

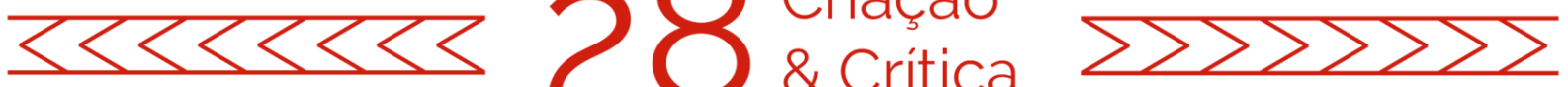

que considerava concluídos (UNSELD, 1983, p. 204). O interesse em publicar se coaduna com o desejo de ser lido, de ler a si mesmo, de produzir com o seu corpo-escrito efeitos, de perpetuar a sua existência espacial e temporalmente. Para tanto, é exigido que ele fique junto da sua escrivaninha, dê forma a esse corpo escritural que visa, acima de tudo, a uma resposta devocional do mundo, a reverenciar e estimar sua existência. Como já apontamos antes, Kafka nunca rompeu definitivamente com o mundo exterior, e tanto o seu desejo de clausura quanto seu alheamento forçado fazem também parte da retórica do artista, mas não deixa de chamar atenção o resultado desse discurso, que é, de fato, a gestão de um novo corpo, diferente, escrito. Ou seja, se é por escrito que a sua melhor feição se revela, é essa pessoa, isto é, essa pessoa-escrita, que deve ser comunicada e (re-)integrada ao mundo.

\section{Referências}

ARISTÓTELES. Poética. Trad. Eudoro de Sousa. 4a․ ed. Imprensa Nacional | Casa da Moeda, 1994.

BINDER, Hartmut. Kafka in neuer Sicht: Mimik, Gestik und Personengefüge als Darstellungsformen des Autobiographischen. Stuttgart: Metzler, 1976.

BROD, Max. Franz Kafka. Eine Biographie. Frankfurt am Main u. Hamburg: Fischer Bücherei KG, 1963.

CAMPE, Rüdiger. Die Schreibszene, Schreiben. In: ZANETTI, Sandro (Hrsg.). Schreiben als Kulturtechnik. 2. Aufl. Berlin: Suhrkamp, 2015. pp. 269-282.

CANETTI, Elias. O outro processo: as cartas de Kafka a Felice. Trad. de Herbert Caro. Rio de Janeiro: Espaço e Tempo, 1988.

FLAUBERT, Gustave. Cartas exemplares. Trad. Carlos Eduardo Lima Machado. Rio de Janeiro: Imago Ed., 2005.

GOETHE, Johann Wolfgang. Memórias: poesia e verdade. Porto Alegre: Globo, 1971.

GRÄSER, Albert. Das literarische Tagebuch: Studien über Elemente des Tagebuchs als Kunstform. Saarbrücken: West-Ost Verlag, 1955.

GRILLPARZER, Franz. Grillparzers Briefe und Tagebücher: Eine Ergänzung zu seinen Werken. Hrsg. von Carl Glossy und August Sauer. Band 1. Sttuttgart-Berlin: J. G. Cotta, 1903.

JURGENSEN, Manfred. Das fiktionale Ich: Untersuchungen zum Tagebuch. Bern: A. Francke AG Verlag, 1979.

KAFKA, Franz. Aforismos reunidos. Trad. Modesto Carone. São Paulo: Instituto Moreira Salles, 2012.

. Briefe. 1900-1912. Hans-Gerd Koch. (Hrsg.) Frankfurt am Main: S. Fischer, 1999.

Briefe. 1902-1924. In: Gesammelte Werke. Max Brod. (Hrsg.) Frankfurt am Main:

S. Fischer, 1958. 

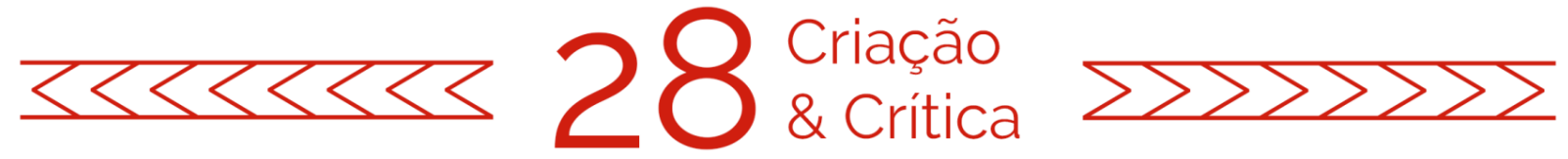

Verlag, 2015.

2013.

. Carta ao pai. 15 a ed. Trad. Modesto Carone. São Paulo: Companhia das Letras,

Kafka. Diários. Trad. Isabel Castro Silva. Lisboa: Relógio D’Água Editores, 2014.

Hochzeitsvorbereitungen auf dem Lande und andere Prosa aus dem Nachlaß.

Max Brod. (Hrsg.) Gesammelte Werke. Frankfurt am Main: S. Fischer, 1966.

Tagebücher. Kommentarband. Nach der kritischen Kafka-Ausgabe herausgegeben von Hans-Gerd Koch, Michael Müller und Malcolm Pasley. Frankfurt am Main: S. Fischer, 1990.

$\mathrm{KOCH}$, Hans-Gerd. (Hrsg.) "Als Kafka mir entgegenkam...” Erinnerungen an Franz Kafka. Berlin: Verlag Klaus Wagenbach, 1995.

LUHMANN, Niklas. Die Gesellschaft der Gesellschaft. Frankfurt am Main: Suhrkamp, 1997.

ROTHER, Andrea. "Hier muss ich mich festhalten ...". Die Tagebücher von Franz Kafka: Ein literarisches Laboratorium 1909-1923. 2007. 252 f. Tese - Universität Berlin, Berlin, 2007.

SCHÄRF, Christian. Franz Kafka: poetischer Text und heilige Schrift. Göttingen: Vandenhoeck \& Ruprecht, 2000.

SCHNEIDER, Wolfgang. "Liebste, ich lese nämlich höllisch gerne vor". In: Literaturen. Das Journal für Bücher und Themen. 06|08. Juni 2008. Leben als Werk. Franz Kafka. Berlin: Friedrich, 2008. pp. 12-29.

SIMON, Ralf (Hrsg.). Grundthemen der Literaturwissenschaft: Poetik and Poetizität. Berlin/Boston: De Gruyter, 2018.

STACH, Reiner. Kafka. Die frühen Jahre (1883-1910). 4. Auf. Frankfurt am Main: S. Fischer Verlag, 2015.

. Kafka. Die Jahre der Entscheidungen (1910-1915). $7^{\circ}$ Auf. Frankfurt am Main: S.

Fischer Verlag, 2017a.

. Kafka. Die Jahre der Erkenntnis (1916-1924). 4. Auf. Frankfurt am Main: S.

Fischer Verlag, 2017b.

THIEBERGER, Richard. Schreiben und Sprechen. In: BINDER, Hartmut. (Hrsg) KafkaHandbuch in zwei Bänden. Das Werk und seine Wirkung. Band 2. Stuttgart: Alfred Kröner Verlag, 1979. pp. 197-198.

UNSELD, Joachim. Franz Kafka. Ein Schriftstellerleben. Die Geschichte seiner Veröffentlichungen. München: Carl Hanser Verlag, 1983.

Recebido em: 23/07/2020

Aceito em: $31 / 10 / 2020$

Referência eletrônica: FREITAS RUSSO, Sâmella Michelly. O corpo-escrito e o corpolido de (e por) Franz Kafka. Criação \& Crítica, n. 28, p., dez. 2020. Disponível em: $<$ http://revistas.usp.br/criacaoecritica>. Acesso em: dd mmm. aaaa. 